\title{
DEVELOPMENT OF AN INTELLIGENT TUTORING SYSTEM FOR DESIGN EDUCATION
}

\author{
Lukas Valentin HOPPE, Stefan PLAPPERT, Paul Christoph GEMBARSKI and Roland \\ LACHMAYER \\ Leibniz University Hannover, Institute of Product Development, Germany
}

\begin{abstract}
To develop problem-solving skills during engineering studies, students must be given the opportunity to act independently and to apply their expertise in professional application situations with feedback that promotes learning. Although practical projects in university teaching deal with real-world problems, individual support and promotion of the students is often difficult due to a lack of personnel and time. Asynchronous learning methods such as e-learning platforms, on which exercises can be made directly available to students, offer a supplement to this. Since the problems of design theory do not contain a unique correct solution but allow a multitude of valid results, the simple true/false question formats of most platforms are unsuitable for the evaluation of design tasks. In this paper a system architecture is presented which provides students with asynchronous design tasks, automatically evaluates solution variants and thus supports the solution process individually by direct feedback. The functionality of the described system was verified and tested by several students, which allowed to demonstrate the usability of the system in the context of education. A subsequent evaluation presents the strengths and weaknesses of the task and the feedback generated by the system.
\end{abstract}

Keywords: Design theory, intelligent tutoring system, learning platform, knowledge-based engineering, asynchronous learning

\section{INTRODUCTION AND MOTIVATION}

To develop problem-solving skills that are important for practice, students must be offered opportunities to act independently and to apply their specialized knowledge in professional application situations with feedback that promotes learning. Individual support and promotion of students in university teaching is often not possible due to lack of personnel and time [1]. For the training of design engineers, learning to develop a product and to define its shape plays a central role [2]. The use of eLearning platforms in design theory offers new possibilities for this [3]. Although the platforms offer a certain framework for task processing, this is usually limited to simple true/false question formats, which can be solved by drag-and-drop, multiple choice or assignment. Unlike in mathematics, for example, the problems of design theory do not contain a definite correct solution, but a variety of valid results. Thus, the requirements for a product can lead to different solution variants. Therefore, designs cannot be compared with a single correct solution, but can only be assigned to a valid solution space which contains a set of feasible variants that fulfil the requirements of the design task [4]. Teaching and learning research are largely agreed that learning with such challenging problems requires additional instructional support [1]. In this paper, we will investigate how an asynchronous learning system can be developed to provide students with an opportunity to practice the design process, supplemented by individual feedback, during lectures. The focus of the design analysis is on conformity to standards and compliance with geometric task restrictions.

\section{SUPPORT OF ASYNCHRONOUS LEARNING BY INTELLIGENT TUTORING SYSTEMS}

The main task of asynchronous learning is to provide learning materials parallel to lectures, which the learner can access and work on according to individual learning preferences regarding time of day, content and learning speed. In contrast to synchronous learning in lectures or exercises, the student is not confronted with his learning materials but can access them selectively and actively [5]. A widespread 
possibility of asynchronous learning is the use of eLearning platforms, which are becoming increasingly important in university education [6]. Today many courses are organized and administered via open source learning management systems like ILIAS, Moodle or StudIP and thus represent a supplement to lectures and exercises. The purpose of eLearning platforms is mainly to provide learning content online and thus make it accessible to many learners independent of time and place [7], [8]. Various forms of media can be used for this purpose, such as videos, literature or sound recordings, which offer a comprehensive content of learning materials. However, when using eLearning platforms, in contrast to traditional teaching, the student must be self-motivated to learn and does not receive any direct feedback on the learning process [7], [8]. In addition, many learning platforms offer a possibility to interact with other students or their teachers in forums or chats [9]. A further offer of some learning platforms (e.g. ILIAS and Moodle) is also the processing of quiz questions for exam preparation and even the possibility to conduct whole exams online.

In contrast to asynchronous learning methods, in which the learning material is only made available to the learners, the intelligent tutoring system (ITS) is a learning software that actively supports the learning process itself [10]. The ITS automatically generates an individual and detailed feedback for the learner during the learning activity [1]. The task of ITS is to enable effective learning with the help of a computer and without the support of a human teacher. Thus, for example, the consolidation of knowledge acquired in lectures or the processing of homework can be usefully supported by an ITS [11]. The system assists the students' progress and collects information about the individual approach to finding solutions. As the behaviour of the student during the learning process is monitored and evaluated, this information can be used to generate hints. This procedure is already used in computer science for training code programming [12]. ITS in parallel with lectures can also be beneficial for the teacher, as he or she receives information about problems and common mistakes and can therefore detect and correct possible weaknesses of his or her lecture.

In order to combine the advantages of asynchronous learning and an ITS, it is possible to embed an ITS in a learning platform (Figure 1) so that the learner can access learning materials and work on tasks individually, independent of time and place [13]. With the help of the ITS, his or her learning process is accompanied by direct feedback. By registering the student on the learning platform, his or her progress can be managed and assessed in a personalized manner. Direct and individual feedback on learning activities is intended to motivate the learner to apply and extend his or her existing knowledge. To do this, the learner can access a variety of learning materials on learning platform to solve the tasks.

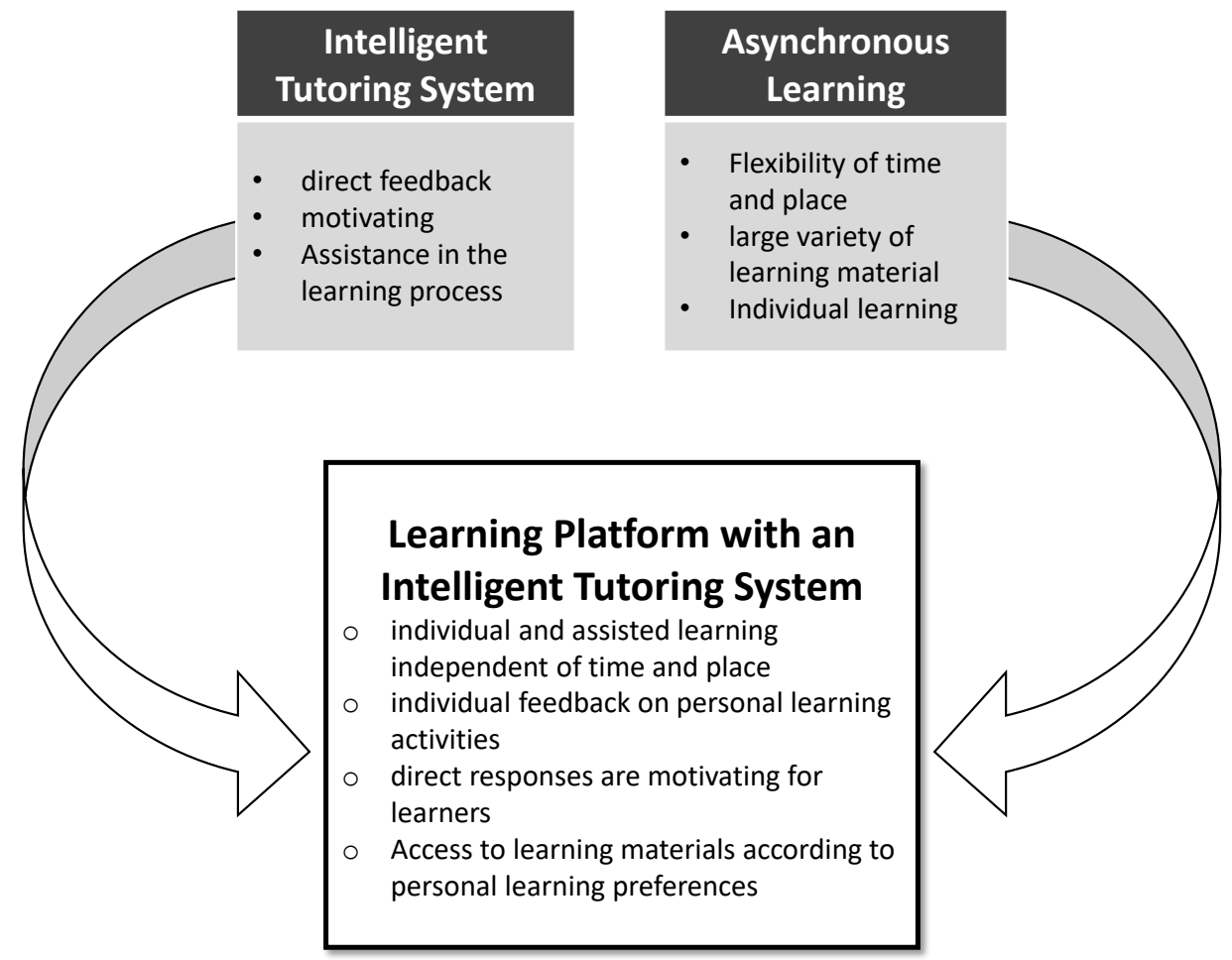

Figure 1. Integration of an Intelligent Tutoring System into a Learning Platform 


\section{STRUCTURE OF THE SYSTEM ARCHITECTURE}

To apply asynchronous learning in combination with an ITS in design theory, a system architecture (Figure 2) has been developed which trains the execution of real problems in design [14]. For development of the ITS, a knowledge-based engineering system (KBES) in Autodesk Inventor was set up as a basic framework. In this system, the function of a knowledge-based system (KBS), which applies expert knowledge in a computer program and solves complex problems with the help of artificial intelligence (AI) techniques, is additionally extended by the capabilities of computer-aided analysis (CAE) and computer-aided design (CAD) [15]. The developed ITS is divided into four modules: knowledge base, feature recognition, inference engine and explanation module.

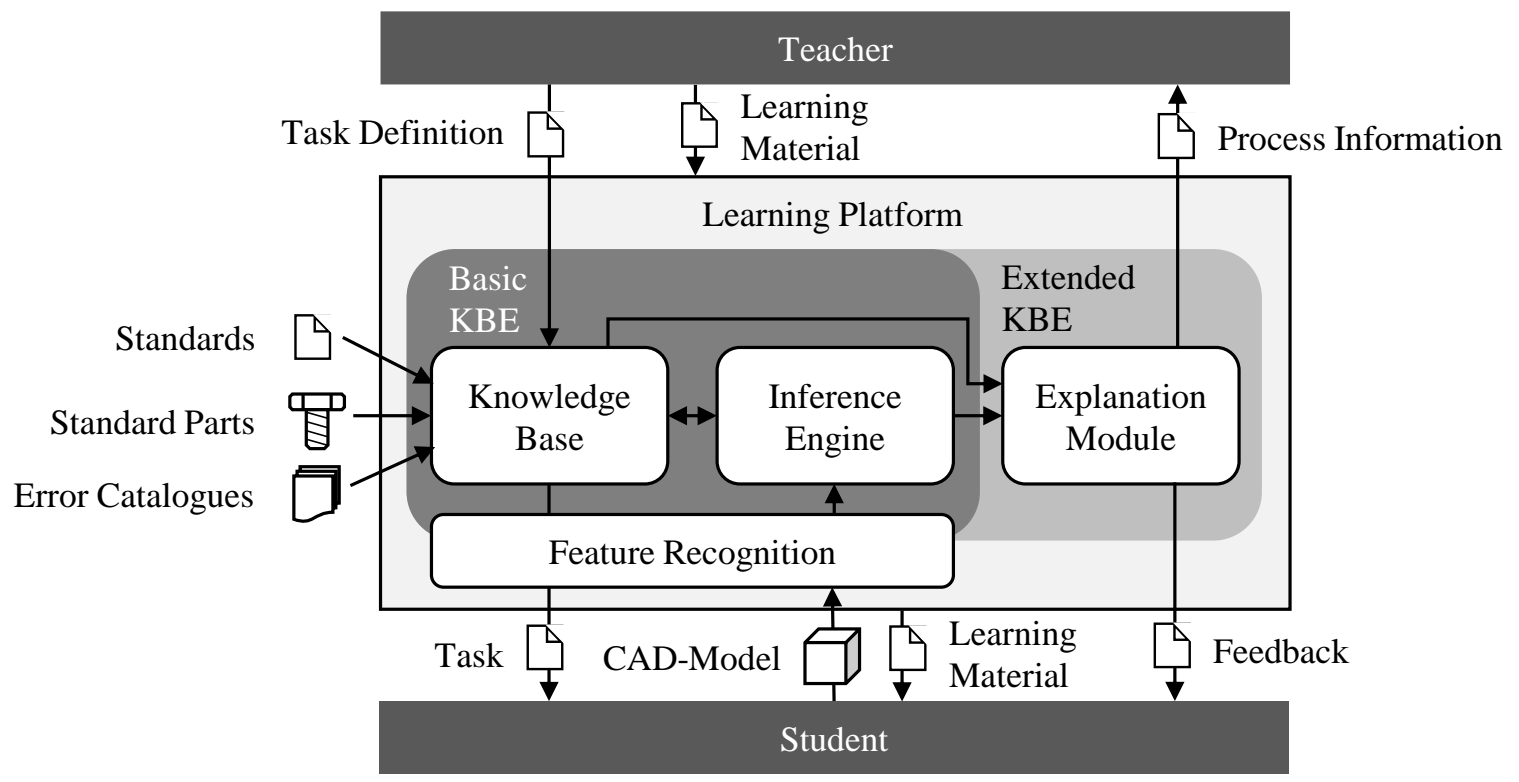

Figure 2. Architecture of the Intelligent Tutoring System embedded into a Learning Platform

- The knowledge base is used to store expert knowledge in the system. For this purpose, Excel tables are used, in which the data of standard parts and standard catalogues are summarised. The knowledge base is filled by the teacher with the knowledge required for the design task to check the correct use of standards and standard parts. The knowledge base thus represents the range of all possible solutions, i.e. the valid solution space of the design task. In addition, parameters are used to store an error catalogue that considers the restrictions of the task and thus defines the limits of the possible solutions.

- The feature recognition represents the environmental interface of the system. It can import CAD models and analyse them regarding their geometry and the design elements used. A Visual Basic for Applications (VBA) macro developed for this purpose checks the surfaces of the CAD model and saves the geometry as a parameter set.

- The inference engine is used to compare the read-in part geometry of the feature recognition with the valid solutions of the knowledge base. For this purpose, a program was developed using the Inventor internal programming language iLogic, which compares the actual and target values. The possible errors are stored and forwarded to the explanation module.

- The explanation module is an extension of the KBES and provides the link between feature recognition and the knowledge base. In order to not only point out to the user of the system the errors in his or her design, but also to offer support for improvement, the error is extended by hints from the error catalogue, and feedback is thus generated. In addition, the module summarizes the students' errors and stores the data for the teacher.

The developed tutoring system will be embedded in a learning platform, so that students can use the system online according to their own learning preferences, independent of time and place, following a personalised registration. After students have completed the task in Autodesk Inventor, they can upload their CAD solution to the platform. With the help of the KBES, the solution is immediately analysed, and feedback is generated. This process can be repeated by the student, so that for each design solution of the student an individual and direct feedback is generated, which should increase the motivation of 
the student. The degree of detail of feedback is increased step by step as the number of solution attempts increases, so that the student is not discouraged in the learning process. Additional learning materials are available to students on the learning platform for working on the tasks. Teachers can use the data stored by the system to track the learning progress of the students, so that frequent errors in lectures can be picked up and discussed.

\section{APPLICATION AND EVALUATION OF THE INTELLIGENT TUTORING SYSTEM}

To test the developed system architecture a prototype task was implemented, which includes the design of a gear shaft. To fulfil the task, a shaft with two bearing seats, two sections for torque transmission and all design elements for force transmission and part safety must be created. To check the used standard parts, the standards of bearings, circlips and keyways to be used are specified. Furthermore, the applicable standard for undercuts on functional surfaces is defined as a design element. In addition, the space available for the shaft is limited; this must not exceed a diameter range of $8-50 \mathrm{~mm}$ and a bearing distance of $80 \mathrm{~mm}$. A mechanical design of the shaft by means of a strength calculation is not integrated into the task.

Using test cases, the system architecture for the shaft design was verified so that it meets the required technical requirements [14]. In the next step, the system is validated by several participants to determine which weaknesses the system has and where there is potential for optimization. The participants are advanced students of mechanical engineering, who support the design theory at the university as student research assistants. This has the advantage that they have both a student-typical approach to problem solving as well as a wealth of experience in design theory with which they can better classify and evaluate the feedback from the tutoring system.

To validate the system, the task of designing a gear shaft was assigned to the participants. The participants worked out an individual solution, which was then evaluated by the tutoring system. The feedback generated in this way was returned to the participants. After the student research assistants had analysed their individual feedback, an evaluation form was filled out by them and then evaluated by the authors. An example of the generated solution variants is shown in figure 3.

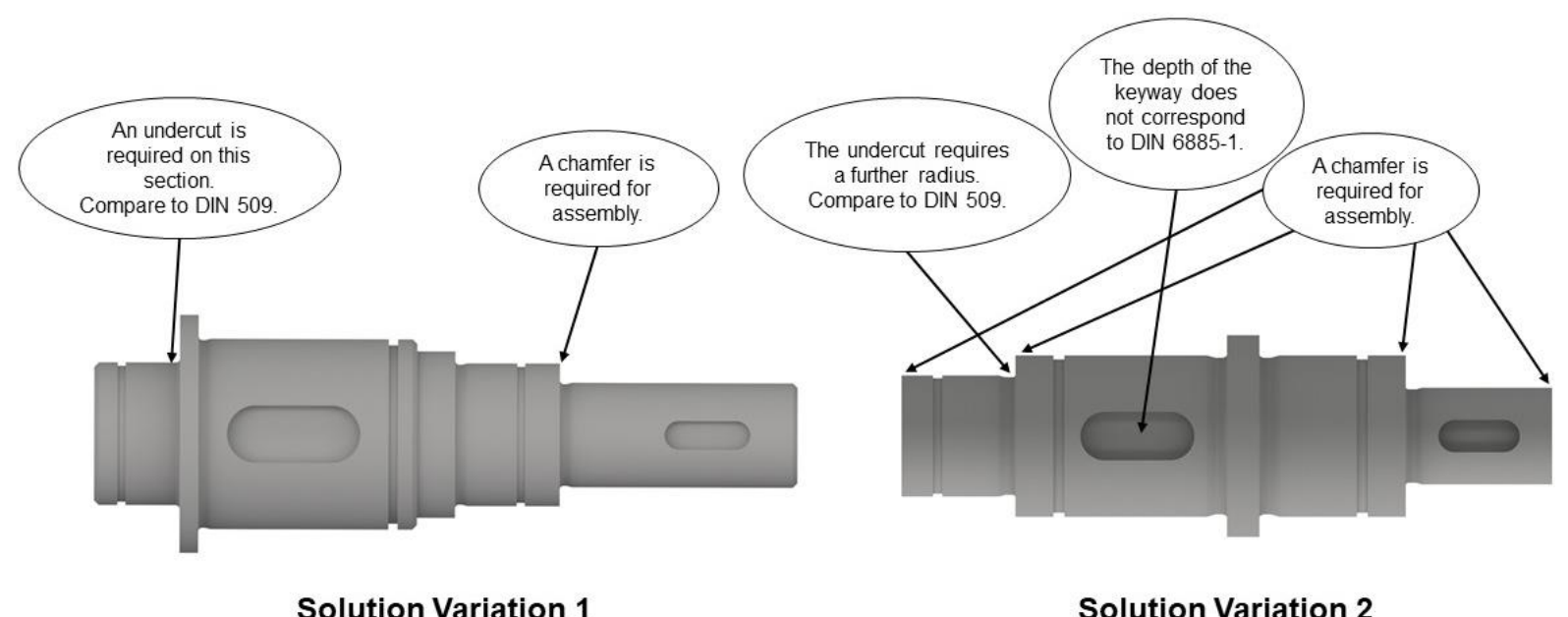

Figure 3. Feedback of test cases for the example task

The generated designs and the evaluations show that the problem definition provided different solution variants. In the short questionnaire of the evaluation (Table 1), the participants described the problem definition as understandable and rather open. The student research assistants mentioned that they had to apply the basic knowledge of standard parts and design elements taught in the lectures in order to solve the problem and that the task of designing a shaft design is well suited for applying their expertise. It is noticeable that the level of the tasks was rated as relatively low on average, which is probably due to the expertise of the experienced participants.

According to the assessment of the participants, the system was able to correctly detect most of the errors of their solution variants. The automatically generated feedback from ITS was found to be helpful 
throughout. It is noticeable that some participants mentioned that the tutoring system does not particularly contribute to deepening design knowledge. Here again, one possible explanation would be the high level of knowledge of the advanced participants. On the other hand, this is certainly also due to the limited scope of the prototype task.

Table 1. Evaluation of the Short Questionnaire for the Intelligent Tutoring System

\begin{tabular}{|l|c|}
\hline \multicolumn{1}{|c|}{ Short Questionnaire } & $\begin{array}{c}\text { Average } \\
\text { rating }\end{array}$ \\
\hline The task is formulated in an understandable way. & 1.25 \\
\hline The type of task allows an individual design solution. & 1.88 \\
\hline The level of the task is too easy for design theory and design projects. & 2.25 \\
\hline The task corresponds to the expertise taught in design theory and design projects. & 1.13 \\
\hline To solve the task the learner must deal with standard parts and design elements. & 1.13 \\
\hline The described errors of the system are correct. & 1.50 \\
\hline The system detected all design errors. & 1.63 \\
\hline The feedback is helpful to solve the task. & 1.13 \\
\hline Working with the intelligent tutorial system helps to deepen the design knowledge. & 2.25 \\
\hline
\end{tabular}

Rating scale: From $1=$ agree to $5=$ disagree

In a second part of the evaluation, the participants could answer four questions in more detail in a text field. The questions were aimed at obtaining suggestions for improvements of the system and thus making use of the expertise of the student research assistants. It became clear that the design errors found and described by the system were correct, but in retrospect not all errors of the CAD solutions could be detected. This includes, among other things, the inspection of shoulder surfaces that are too high, which the system has not yet detected, but is necessary for the function of the bearings. As enhancements for the ITS, the student research assistants proposed to take different calculations into account. For this purpose, the task could be extended, for example, by a strength calculation for the correct dimensioning of the shaft or by the calculation of fits for a correct design of tolerances.

\section{CONCLUSIONS}

In this paper a combination of asynchronous learning and an ITS in design theory was presented. The developed ITS offers the possibility that not only design rules are memorized, but the design process can be practiced by students individually. The embedding in a learning platform offers the advantages of independent provision of assisted learning materials as well as individual registration of the user. Only then can the described system architecture generate individual and flexible feedback. The embedding also allows user data to be recorded so that they can be interpreted by the teacher and incorporated into his or her lessons. The evaluation of the evaluation shows that the developed system architecture can analyse CAD data automatically and to detect errors regarding the limitations of the task. The ITS was able to feedback design errors of the solution variants combined with hints to the students and thus support them in the solution process. However, the evaluated results also indicate that the system should be extended to include additional error detection to generate more sophisticated feedback. Moreover, the level of the ITS could be raised by an extension of additional exercises and the work with the tutorial system could lead to a deeper design knowledge of the students.

Future evaluations will determine whether the ITS developed can be used as a supplement in design theory and convey problem-solving skills. To this end, the system is to be extended by further tasks, such as the calculation of the strength of shafts, and subsequently integrated into courses in design theory. This offers the possibility of obtaining a meaningful evaluation of the benefits of ITS from several hundred students.

\section{REFERENCES}

[1] Schulz, C., Sailer, M., Kiesewetter, J., Meyer, C. M., Gurevych, I., Fischer, F. and Fischer, M. R. Fallsimulationen und automatisches adaptives Feedback mittels Künstlicher Intelligenz in digitalen Lernumgebungen. Available: https://www.e-teaching.org/etresources/pdf/ erfahrungsbericht_2017_schulz-et-al_fallsimulationen-und-automatisches-adaptives-feedback- 
mittels-kuenstlicher-intelligenz-in-digitalen-lernumgebungen.pdf [Assessed on 2020, 03 March] (2017) 04 October.

[2] Atman, C. J., Cardella, M. E., Turns, J. and Adams, R. Comparing freshman and senior engineering design processes: an in-depth follow-up study. Design studies, 2005, 26(4), 325-357. https://doi.org/10.1016/j.destud.2004.09.005

[3] Hiekata, K., Yamato, H., Rojanakamolsan, P. and Oishi, W. A Framework for Design Engineering Education with Workflow-based e-Learning System. JSW, 2007, 2(4), 88-95. https://doi.org/10.4304/jsw.2.4.88-95

[4] Gembarski, P. C. and Lachmayer, R. Solution space development: conceptual reflections and development of the parameter space matrix as planning tool for geometry-based solution spaces. International Journal of Industrial Engineering and Management (IJIEM), 2018, 9(4), 177-186. http://doi.org/10.24867/IJIEM-2018-4-177

[5] Hilt, V., Schremmer, C., Kuhmünch, C. and Vogel, J. Erzeugung und Verwendung multimedialer Teachware im synchronen und asynchronen Teleteaching. Wirtschaftsinformatik, 2001, 43(1), 23-33. https://doi.org/10.1007/bf03250779

[6] Treumann, K. P., Ganguin, S. and Arens, M. E-Learning in der beruflichen Bildung, 2012 (VS Verlag für Sozialwissenschaften).

[7] Zhang, D., Zhao, J. L., Zhou, L. and Nunamaker Jr, J. F. Can e-learning replace classroom learning? Communications of the ACM, 2004, 47(5), 75-79. https://doi.org/10.1145/986213.986216

[8] Ruiz, J. G., Mintzer, M. J. and Leipzig, R. M. The impact of e-learning in medical education. Academic medicine, 2006, 81(3), 207-212.

[9] Brooks C., Greer J., Melis E. and Ullrich C. Combining ITS and eLearning Technologies: Opportunities and Challenges. In: Ikeda M., Ashley K.D., Chan TW. (eds) Intelligent Tutoring Systems, ITS 2006. Vol. 4053, pp. 278-287. (Springer, Berlin, Heidelberg) https://doi.org/10.1007/11774303_28

[10] Chakraborty, S., Roy, D. and Basu, A. Development of knowledge based intelligent tutoring system. Advanced knowledge-based systems: model, applications \& research, 1, 2010, pp. 74100.

[11] VanLehn, K. The relative effectiveness of human tutoring, intelligent tutoring systems, and other tutoring systems. Educational Psychologist, 2011, 46(4), 197-221. https://doi.org/10.1080/00461520.2011.611369

[12] Paaßen, B., Hammer, B., Price, T. W., Barnes, T., Gross, S. and Pinkwart, N. The continuous hint factory-providing hints in vast and sparsely populated edit distance spaces. Journal of Educational Data Mining, 10 (2018) 1-35.

[13] Rosi, M., Stankov, S. and Glavinic, V. Intelligent tutoring systems for asynchronous distance education. In 2000 10th Mediterranean Electrotechnical Conference. Information Technology and Electrotechnology for the Mediterranean Countries. Vol. 1, May 2000, pp. 111-114 (IEEE). https://doi.org/10.1109/melcon.2000.880380

[14] Plappert, S., Hoppe, L.V., Gembarski, P.C. and Lachmayer, R. Application of Knowledge-based Engineering for Teaching Design Knowledge to Design Students (accepted for Design Conference 2020, in publication)

[15] Milton, N.R. Knowledge Technologies. 2008 (Polimetrica sas, Monza). 